\title{
DESAFIOS DA POLÍTICA DE HABITAÇÃO DE INTERESSE SOCIAL EM SALVADOR
}

\section{ARTIGO ORIGINAL}

TRINDADE, Andrezza Morais ${ }^{1}$

BARRETO, Renée Buzahr Fontes ${ }^{2}$

TRINDADE, Andrezza Morais. BARRETO, Renée Buzahr Fontes. Desafios da política de habitação de interesse social em Salvador. Revista Científica Multidisciplinar Núcleo do Conhecimento. Ano 05, Ed. 03, Vol. 05, pp. 79-101. Março de 2020. ISSN: 2448-0959, Link de acesso: https://www.nucleodoconhecimento.com.br/arquitetura/politica-de-habitacao

\section{RESUMO}

O presente texto aborda a análise da implantação da Política de Habitação de Interesse Social em Salvador a partir de 1960. O estudo inicia-se conceituando o que é moradia digna ou moradia adequada e contextualiza quando se expandiu, no Brasil, essa consciência sobre o habitar. Faz-se um breve histórico da Política Habitacional no País, especificamente sobre a capital baiana a fim de entender quais foram as maiores conquistas alcançadas a respeito da habitação de interesse social. Em seguida, são analisados os programas habitacionais vigentes em Salvador e feita uma reflexão sobre os avanços e retrocessos dos Planos Diretores de Desenvolvimento que passaram pelo município. Ao final, é apresentada uma crítica sobre o que ainda precisa ser alcançado em Salvador para que a Política de Habitação de Interesse

${ }^{1}$ Especialista em Planejamento Urbano e Gestão de Cidades pela Universidade Salvador - UNIFACS, Arquiteta e Urbanista graduada pela Universidade Salvador UNIFACS.

${ }^{2}$ Mestra em Arquitetura e Urbanismo pela Universidade Federal da Bahia - UFBA, Urbanista graduada pela Universidade Estadual da Bahia - UNEB. 
Social seja realmente eficiente, propondo, para tanto, um Plano Integrado, pois é fundamental para o desenvolvimento sustentável de uma cidade, e, consequentemente, para a eficácia da política habitacional.

Palavras-chave: Política de Habitação, Moradia Digna, Habitação de Interesse Social, Programas Habitacionais, Plano Diretor de Desenvolvimento.

\section{INTRODUÇÃO}

A Política Nacional de Habitação, o Plano Nacional de Habitação e a Política Municipal de Habitação de Salvador objetivam universalizar o acesso à moradia digna para todos. Diante do exposto, o arcabouço jurídico é muito claro em relação ao acesso à moradia. Contudo, existem desafios enfrentados pela política habitacional que tornam sua aplicação insuficiente para reduzir o déficit habitacional do município de Salvador que serão objeto de discussão deste artigo. Primeiramente, deve-se destacar que moradia digna ou moradia adequada é a habitação que proporciona exercer os demais direitos humanos. Isto inclui as condições adequadas de saneamento básico, mobilidade e infraestrutura urbana, acesso à educação, saúde, trabalho, lazer e padrões urbanísticos e arquitetônicos que respeitam à cultura local (SALVADOR, LEI № 7.400, 2008).

Vale ressaltar que é importante observar que a problemática da habitação de interesse social só teve um reconhecimento como direito fundamental depois da democratização do Brasil, isto é, com a Constituição Federal de 1988, resultado do Movimento Nacional pela Reforma Urbana. Este, por sua vez, foi articulado por grupos sociais, técnicos e alguns atores públicos compromissados, demostrando uma preocupação para com a reforma urbana e com a luta pela renovação dos instrumentos de regulação urbanística. As intervenções feitas entre 1980 e 1990 foram limitadas, devido ao ajuste estrutural no país que tentava evitar o risco de endividamento público (BALTRUSIS; MOURAD, 2014).

Nesse contexto, é preciso destacar que o projeto de lei do Estatuto da Cidade tramitou em 1990, e, dessa forma, acabou sendo promulgado, posteriormente, por meio da Lei 
Federal n.-10.257/2001, esta ficou responsável por instituir diretrizes e instrumentos para cumprimento da função social da cidade e da propriedade urbana, do direito à moradia e à cidade e redefiniu a função do Plano Diretor de Desenvolvimento Urbano (PDDU) (CYMBALISTA; SANTORO, 2009). Em 2003, foi criado o Ministério das Cidades e o Conselho das Cidades objetivando uma maior participação dos diferentes atores das cidades. Segundo Cymbalista e Santoro (2009, p. 7):

Dentre as secretarias do novo ministério foi criada a Secretaria Nacional de Programas Urbanos, que centralizou as ações relacionadas aos Planos Diretores e viabilizou o aumento de escala da construção dos Planos Diretores nos municípios. Para diferenciá-los dos Planos Diretores de desenvolvimento urbano das décadas de 1970 e 1980, estes foram rebatizados de "Planos Diretores Participativos" pelo Ministério das Cidades, ressaltando outra das principais apostas em torno do instrumento.

E, por fim, em 2009 a Política Habitacional foi marcada pela criação do Programa Minha Casa Minha Vida (PMCMV), Lei n.o 11.977/2009, que visava reduzir drasticamente o déficit habitacional. Para subsidiar essa discussão, foram analisados os Programas Municipais Habitacionais de Interesse Social vigentes em Salvador, isto é, o Programa Morar Melhor que proporciona melhorias nas habitações buscando dar dignidade às moradias, o Programa Casa Legal, que objetiva a regularização fundiária em terrenos públicos Municipais ocupados informalmente por população de baixa renda e o Programa Minha Casa Minha Vida e seu rebatimento em Salvador. Posteriormente, será feita uma breve síntese acerca dos avanços e retrocessos dos Planos Diretores de Desenvolvimento Urbano (PDDUs) de Salvador.

A reflexão feita sobre "A cidade que queremos" pela ótica da moradia, realizada na disciplina de Regularização Fundiária da Especialização em Planejamento Urbano e Gestão de Cidades da Universidade Salvador - UNIFACS, em 2016, fez observar que a Política Habitacional aplicada isoladamente não é eficaz para a produção de moradia digna, necessitando de uma análise mais específica sobre as dificuldades enfrentadas na habitação de interesse social em Salvador. Além disso, a implantação 
de empreendimentos habitacionais de interesse social pelo Programa Federal Minha Casa Minha Vida no Município aumentou o empenho em analisar e verificar como a Política de Habitação está sendo implementada na capital baiana.

Com isto, tornou-se necessário investigar como a Política de Habitação está sendo implementada em Salvador. Os objetivos específicos deste artigo são analisar a eficiência dos programas habitacionais vigentes na cidade e fazer uma breve crítica aos PDDUs de Salvador, averiguando se ocorreram avanços no que tange à habitação de interesse social. O caminho metodológico escolhido foi pesquisa e estudo bibliográfico do tema a partir de documentos oficiais, artigos, dissertações e teses. Após a análise dos textos, foi realizada a sistematização dos dados coletados, elaborando, para isso, uma discussão dos conteúdos e reflexões posteriores sobre a importância de fazer e executar um Plano Integrado para que a Política Habitacional possa ser verdadeiramente eficaz.

\section{MORADIA E MORADIA DIGNA}

O mundo, e não menos o Brasil, vive, hoje, uma crise de insegurança de posse, como afirma Rolnik (2012)[3] em um relatório temático à ONU "Informe de la Relatora Especial sobre una vivienda adecuada como elemento integrante del derecho a un nivel de vida adecuado y sobre el derecho de no discriminación a este respecto"[4]. Milhares de pessoas vivem sob ameaça de serem despejadas ou terem seus arrendamentos questionados a qualquer momento pelo ente público ou privado, o que ocasiona no aumento massivo da pobreza e da destruição de comunidades, levando estas pessoas a um estado crítico de vulnerabilidade. O que se pode observar é que as pessoas têm direito a segurança de posse como parte do seu direito à moradia adequada. $\mathrm{O}$ direito à moradia é um direito social reconhecido pela Declaração Universal dos Direitos Humanos em 1948, adotada pela Organização das Nações Unidas (ONU) e reconhecido, no Brasil, apenas com a Constituição Federal de 1988, introduzido na Nossa Lei Maior por força do disposto na Emenda Constitucional no 26, de 14 de fevereiro de 2000 (GONÇALVES, 2013). 
Mas o que é moradia adequada? A moradia adequada é, segundo a definição da Comissão da Organização das Nações Unidas para Direitos Humanos, Econômicos, Sociais e Culturais (1991), muito mais do que uma construção para abrigar. Ela abrange a infraestrutura que deve permitir viver uma vida com dignidade e deve conceder o exercício dos demais direitos básicos do cidadão. A infraestrutura básica ao qual se refere é a segurança de posse (contra remoção forçada), acesso à abastecimento de água potável, energia elétrica, esgotamento sanitário, transporte, acesso fácil e direto a ruas e calçadas, adequação da residência à cultura local e proximidade de equipamentos públicos (ROLNIK, 2014).

Considerando tais fatores, deve-se destacar que a Lei $n .-11.124$ de 2005, que discorre sobre o Sistema Nacional de Habitação de Interesse Social (SNHIS), foi criada a partir do primeiro projeto de lei de iniciativa popular do Brasil, e, dessa forma, enuncia e prevê que dentre seus objetivos está "viabilizar para a população de menor renda o acesso à terra urbanizada e à habitação digna e sustentável" e que deve observar em sua atuação o princípio de moradia digna como direito e vetor de inclusão social. O direito à moradia é fundamental para os desenvolvimentos dos espaços urbanos, dos cidadãos e das comunidades (BRASIL, 2005).

\section{BREVE HISTÓRICO DA POLÍTICA HABITACIONAL NO BRASIL}

A Política Habitacional visa universalizar o acesso à moradia digna a todo cidadão (BRASIL, 2004). Segundo a Política Nacional de Habitação (2004), a Fundação da Casa Popular foi a primeira Política Nacional de Habitação, criada em 1946, que ainda inexperiente, não se fez eficaz devido à pouca produção de moradia no país e à falta de recursos e regras de financiamento. A política de Habitação no período do Golpe Militar de 1964, que durou de 1964 a 1985, de acordo com Júnior e Uzzo (2009), foi implantada pelo Banco Nacional de Habitação $(\mathrm{BNH})$, criando, dessa forma, um sistema de financiamento que permitiu a captação de recursos, sendo representados, portanto, pelo Fundo de Garantia de Tempo de Serviço (FGTS) e, também, pelo Sistema Brasileiro de Poupança e Empréstimo (SBPE). 
Contudo, Segundo Barreto (2016), o resultado não cumpriu seu objetivo principal que era o atendimento à população de baixa renda, na faixa de 0 a 3 salários mínimos, além de ter sido um modelo financeiro inadequado em uma economia com processo inflacionário, e, assim, produziu conjuntos habitacionais distantes dos centros urbanos e sem proporcionar infraestrutura básica, e, ainda, adotou uma uniformização de soluções para todo o território brasileiro. Após um período de forte êxodo rural, que durou entre 1940 a 1991, o qual provocou um rápido aumento da população urbana sem infraestrutura, e, consequentemente, o aumento das desigualdades sociais, foi criado, em 1985, o Movimento Nacional pela Reforma Urbana, que resultou na Constituição Federal de 1988 em busca do direito à cidade justa. Segundo Pena (2016, p. 1):

Movimento Nacional pela Reforma Urbana, que se iniciou com uma série de lutas locais por moradias e ganhou, gradativamente, um escopo de luta pela cidade como um espaço democrático em termos de acessos, educação, cultura, infraestrutura, saúde e segurança. Esse movimento reuniu vários grupos não institucionais, além de federações, sindicatos, arquitetos e uma grande quantidade de intelectuais.

De acordo com Júnior e Uzzo (2009), logo após a Constituinte, o Fórum Nacional de Reforma Urbana, que havia sido criado em 1987, começou a pressionar o Congresso Nacional a regulamentar o Capítulo da política urbana da Constituição Federal, até que, em 2001, foi criada a Lei Federal n` 10.257 , que ficou conhecida como Estatuto da Cidade. Essa Lei fortaleceu a municipalidade brasileira, visto que trouxe princípios jurídicos e administrativos de planejamento e gestão das cidades em busca da promoção do direito à cidade e ao desenvolvimento sustentável. A criação do Ministério das Cidades, em 2003, e, consequentemente, do Conselho das Cidades, possibilitou uma maior participação dos diversos atores das cidades na elaboração e execução de Políticas Públicas. Em 2005, como já citado neste artigo, foi criado o Sistema Nacional de Habitação de Interesse Social e o Fundo Nacional de Interesse Social, fundamentais para aplicação de uma Política de Habitação eficiente. 
O ano de 2009 foi marcado pela criação do Programa Federal Minha Casa Minha Vida (MCMV), Lei $n .$. 11.977/2009. De acordo com Menezes (2016), o objetivo do MCMV é promover a aquisição de novas habitações para famílias de várias faixas de renda, dentre as quais a Faixa 1 atende famílias com renda familiar bruta de zero a $\mathrm{R} \$ 1.800,00$ (um mil e oitocentos reais), com recursos do Fundo de Arrendamento Residencial (FAR). Segundo o Programa MCMV (2016), para atender as demais faixas de renda, com limite de até $R \$ 6.500,00$ (seis mil e quinhentos reais), o programa oferece financiamento direto junto à Caixa Econômica Federal (CAIXA).

O Plano Diretor de Desenvolvimento Urbano vigente em Salvador, Lei n.ำ 9.069 /2016, traz um capítulo sobre o Planejamento da Política de Habitação de Interesse Social. Pode-se destacar avanços dentre os assuntos abordados: a importância de ações metropolitanas para solução de problemas e a reversão das tendências indesejáveis por meio da oferta de alternativas de atendimento habitacional que tenham qualidade e quantidade adequadas. Isto revela uma maturidade sobre o conhecimento da problemática vivida na cidade e mostra que o arcabouço jurídico é claro no que se deseja alcançar. O desafio enfrentado, então, é como harmonizar a legislação e a sua prática.

\section{POLÍTICA DE HABITAÇÃO DE INTERESSE SOCIAL EM SALVADOR}

O processo rápido de urbanização em Salvador se deu, de forma geral, na mesma época e modelo das demais capitais do Brasil. Segundo Villagra e Oliveira (2006), em 1940 a cidade passou a receber trabalhadores rurais dispensados pela decadente cultura açucareira do Recôncavo baiano e pela estagnação da produção de cacau do sul do estado. Entre 1940 e 1950 a população de Salvador cresceu 43,7\% passando dos 417.000 habitantes (SOUZA, 1990). Entretanto, tratava-se de uma população rural sem qualificação para os trabalhos encontrados na cidade e de baixo poder aquisitivo, o que resultou em uma urbanização sem infraestrutura e sem ordenamento do uso e ocupação do solo, e, consequentemente, em uma grande segregação social espacial. 
Segundo Souza (2002), durante 1960 e 1980 foram produzidas habitações para população de baixa renda a partir do financiamento do $\mathrm{BNH}$, havendo uma consolidação do mercado imobiliário. A década de 1980 foi marcada pela redemocratização do Brasil e extinção do $\mathrm{BNH}$, e, dessa forma, a Política de Habitação estava fragmentada e em lugar dos programas estaduais e municipais surgiram programas locais e alternativos. Segundo Baltrusis e Mourad (2014), entre 1970 e 1990 a expansão urbana de Salvador foi influenciada pela criação de novos eixos com a inauguração da Avenida Luiz Viana Filho, com a ligação do Aeroporto ao Centro Administrativo à Estação Rodoviária (1974) e com o Shopping Iguatemi (1975), o que culminou no surgimento de comunidades de ocupações irregulares como a Sussuarana e a Pela Porco. Baltrusis e Mourad (2014) apud Villagra e Oliveira (2006, p. 32), destacam:

A instalação do Shopping Iguatemi criou uma nova centralidade e a "abertura de novas avenidas que se tornaram fatores decisivos para o surgimento de conjuntos habitacionais e a ocupação de espaços, até então eminentemente rurais".

De acordo com Baltrusis e Mourad (2014), a partir de 1995 houve uma retomada de investimentos em programas habitacionais, destacados na Figura a seguir.

Figura 1 - Programas habitacionais do Governo do Estado da Bahia para o Município de Salvador entre 1995 e 2006

Quadro 1 - Programas Habitacionais do Governo do Estado da Bahia para o Município de Salvador entre 1995 e 2006

\begin{tabular}{|l|l|}
\hline Programas & \multicolumn{1}{c|}{ Sintese } \\
\hline Viver Melhor & $\begin{array}{l}\text { Lançado em 1995, com o objetivo de melhoria da qualidade } \\
\text { de vida, especialmente em assentamentos subnormais e favelas. } \\
\text { Parceria com o Governo Federal e recursos do Orçamento } \\
\text { Geral da Uniâo (OGU) - Habitar Brasil e o Governo Estadual }\end{array}$ \\
\hline $\begin{array}{l}\text { Habitacional } \\
\text { do Servidor } \\
\text { Público }\end{array}$ & $\begin{array}{l}\text { Lançado em 1997, com o objetivo de oferecer moradias } \\
\text { subsidiadas aos servidores públicos estaduais com mais de dois } \\
\text { anos de efetivados e renda familiar de até 12 SM's e que nâo } \\
\text { fossem proprietários de algum outro imóvel financiado pelo SFH }\end{array}$ \\
\hline $\begin{array}{l}\text { Infraestrutura } \\
\text { em conjuntos } \\
\text { habitacionais }\end{array}$ & $\begin{array}{l}\text { Lançado em 1997, vinculado ao Pró-Moradia (Resoluçâo 211/96) } \\
\text { com o objetivo de reduzir a inadimplência, através da realizaçâo } \\
\text { de obras de conservação e infraestrutura, construção de } \\
\text { equipamentos comunitários e embelezamento, como forma de } \\
\text { valorizar esses conjuntos }\end{array}$ \\
\hline
\end{tabular}


Fonte: Baltrusis e Mourad (2014) apud Sedur-BA (2013)

Em 2008 foi criado o primeiro Plano de Habitação do Brasil: o Plano Municipal de Habitação de Salvador (PMHIS) 2008-2025, adequando-se ao Sistema Nacional de Habitação de Interesse Social, que planejava usar recursos do Governo Estadual e Federal e financiamentos de agências internacionais (Salvador, 2008) para promover a melhoria habitacional (requalificação de assentamentos precários, cortiços), a regularização fundiária e o acesso à moradia, segundo a Secretaria Municipal de Habitação de Salvador (2008). Até o final da administração do então Prefeito João Henrique de Barradas Carneiro em 2012, alguns programas foram criados para mitigar o problema da moradia para a população vulnerável.

Segundo Barreto (2016), o Projeto de Urbanização Integrada em Poligonal Inserida na Localidade de Mata Escura e a Urbanização Integrada de Baixa Fria em São Marcos, Pau da Lima são algumas das ações voltadas a amenizar tal problemática. Contudo, muitos deles possuíam exigências documentais e burocráticas que dificultavam o financiamento além da quantidade insuficiente de produção de moradia popular e de um número pequeno de melhorias habitacionais e urbanísticas, como destacam Baltrusis e Mourad (2014). A seguir, na figura 2, encontram-se os Programas Habitacionais e Salvador vigentes em 2011, o que evidencia a diversidade de recursos e ações. 
Figura 2 - Programas habitacionais em Salvador - 2011

Quadro 2 - Programas Habitacionais em Salvador - 2011

\begin{tabular}{|c|c|c|}
\hline Recursos & Programa & Modalidade \\
\hline Governo Federal e Municipal & $\begin{array}{l}\text { Projetos prioritários de } \\
\text { Investimento (PPI) }\end{array}$ & $\begin{array}{l}\text { Estudos, planos e projetos de urbanizaçāo de } \\
\text { assentamentos precários }\end{array}$ \\
\hline $\begin{array}{l}\text { FNHIS (PAC 2) } \\
\text { Programa Minha Casa, Minha Vida }\end{array}$ & & $\begin{array}{l}\text { Urbanizaçâo de assentamentos } \\
\text { precários }\end{array}$ \\
\hline $\begin{array}{l}\text { Ministério da Integração } \\
\text { Nacional e Município }\end{array}$ & Provisảo de moradia & $\begin{array}{l}\text { Construçâo de casas para os desabrigados da } \\
\text { chuva - Jardim Campo Verde }\end{array}$ \\
\hline Municipal e Estadual & & $\begin{array}{l}\text { Produçâo de } 60 \text { unidades } \\
\text { habitacionais na Vila Preservaçāo }\end{array}$ \\
\hline $\begin{array}{l}\text { Fundaçăo Nacional de Saúde- } \\
\text { Funasa Emenda Parlamentar e } \\
\text { recursos do Município }\end{array}$ & Melhorias habitacionais & $\begin{array}{l}\text { Construçâo de } 130 \text { unidades sanitárias na } \\
\text { localidade de Nova Constituinte }\end{array}$ \\
\hline $\begin{array}{l}\text { Ministério das Cidades } \\
\text { FNHIS/PAC } 2 \text { e Municipio }\end{array}$ & Urbanizaçāo integrada & $\begin{array}{l}\text { Obras de saneamento básico, contençáo de } \\
\text { encostas, construçâo de equipamentos } \\
\text { comunitários produção de unidades } \\
\text { habitacionais para relocação de famílias }\end{array}$ \\
\hline $\begin{array}{l}\text { Ministério das Cidades: } \\
\text { FNHIS e do Municipio }\end{array}$ & Urbanizaçăo integrada & Urbanizaçâo integrada \\
\hline Tesouro municipal - custeio & $\begin{array}{c}\text { Regularizaçäo urbanística } \\
\text { e fundiária }\end{array}$ & $\begin{array}{l}\text { De áreas públicas municipais mediante a } \\
\text { outorga da Concessáo de Uso Especial para } \\
\text { Fins de Moradia (Cuem) e da Concessão de } \\
\text { Direito Real de Uso (CDRU) }\end{array}$ \\
\hline $\begin{array}{l}\text { Aliança de Cidades / } \\
\text { Banco Mundial }\end{array}$ & $\begin{array}{l}\text { Regulamentação das Zeis } \\
\text { de Salvador }\end{array}$ & \\
\hline Programa Habitar Brasil/ BID & Plano de bairro & \\
\hline $\begin{array}{l}\text { Aliança de Cidades / } \\
\text { Banco Mundial }\end{array}$ & $\begin{array}{l}\text { Regulamentaçâo das Zeis } \\
\text { de Salvador }\end{array}$ & $\begin{array}{l}\text { Planos de Regularização para quatro ZEIS } \\
\text { ocupadas (Sấo Marcos, Pau da Lima, Centro } \\
\text { Histórico }-7^{\text {a }} \text { Etapa, Mata Escura/Calabetäo) }\end{array}$ \\
\hline Programa Habitar Brasil / BID & & $\begin{array}{l}\text { Atualizaçâo do levantamento e mapeamento } \\
\text { dos vazios urbanos }\end{array}$ \\
\hline Programa Habitar Brasil / BID & & $\begin{array}{l}\text { Levantamento da situaçảo fundiária das Zonas } \\
\text { Especiais de Interesse Social - ZEIS }\end{array}$ \\
\hline Municipal & $\begin{array}{c}\text { Planejamento e } \\
\text { fortalecimento institucional }\end{array}$ & $\begin{array}{l}\text { Prestação de serviço de assistência técnica em } \\
\text { arquitetura para famílias de baixa renda }\end{array}$ \\
\hline
\end{tabular}

Fonte: Sedur (BA)

Fonte: Baltrusis e Mourad (2014) apud Sedur-BA (2013)

\section{PROGRAMAS HABITACIONAIS VIGENTES EM 2016 EM SALVADOR}

\subsection{PROGRAMA CASA LEGAL}

Casa Legal é um Programa Municipal de regularização fundiária gratuito criado em 2013 para titular as habitações situadas em terreno público municipal ocupado 
informalmente por famílias de baixa renda. Segundo a Secretaria de Infraestrutura e Obras Públicas (SEINFRA) (2016):

O objetivo do programa é a salvaguarda da segurança de posse dos ocupantes por meio da Escritura de Legalização emitida pela SEINFRA. Vale ressaltar a importância do registro do supracitado documento no Cartório de Registro de Imóveis, para que os direitos dos concessionários sejam respeitados, tais como: averbar a construção do terreno à unidade habitacional, transmitir por causa mortis e doação inter vivos, quando for o caso, titulação para melhoria habitacional através das agências bancárias. A prefeitura Municipal de Salvador, através das extinta Secretaria Municipal de Infraestrutura, Habitação e Defesa Civil (SINDEC), cumpriu a meta pactuada para gestão municipal 2013-2016 com a emissão de 30mil títulos de posse.

O instrumento jurídico para Regularização Fundiária utilizado pelo Programa Casa Legal é a Concessão de Uso Especial para fins de Moradia (CUEM), regulamentada pela Lei Municipal № 6099/2002 e a Concessão de Direito Real de Uso - CDRU regulamentada pelo Decreto-Lei ํo 271/1967, Emenda ํo 16 à Lei Orgânica do Município do Salvador. Os critérios para participar do programa são:

Imóvel situado em área urbana pertencente ao Município;

Ocupar área de até $250 \mathrm{~m}^{2}$;

Utilizar o terreno para fins de moradia do possuidor ou de sua família;

Não ser proprietário ou concessionário de outro imóvel urbano ou rural;

Não ter sido beneficiado pelo programa de regularização fundiária;

Possuir uma renda familiar de até 06 salários mínimos (SINDEC, 2016).

Não existem dados de mesma categoria para a comparação da informalidade habitacional em Salvador nos últimos dez anos. Contudo, sabe-se que o Déficit 
Habitacional da Região Metropolitana de Salvador (RMS) em 2007 era de 141mil unidades e em 2010 o dado de déficit habitacional é pertencente somente ao Município de Salvador, com 106 mil unidades, sendo a quarta capital brasileira com maior déficit. Já em 2014 o Déficit Habitacional da RMS era de 107mil unidades (FUNDAÇÃO JOÃO PINHEIRO, 2016). Além disso, segundo Salvador (2008), em 2008 a informalidade no solo urbano Municipal alcançava $60 \%$ da população soteropolitana e, de acordo com Salvador (2015), em 2015, 22\% da porção territorial do Município foi ocupada por assentamentos precários e informais, definidos como Zonas Especiais de Interesse Social (ZEIS). O Plano Salvador 500 PDDU - LOUOS, Salvador do Futuro: Território da Inclusão e das Oportunidades (2015, p. 43) destaca:

Também é expressiva a porção do território ocupado por assentamentos subnormais definidas como Zonas Especiais de Interesse Social - ZEIS, que correspondem a 22\% da macroárea. Deve-se ressaltar, entretanto, que alguns assentamentos já atingiram um nível de consolidação e estruturação que permitem o seu tratamento como bairros populares, apesar da insuficiência dos serviços e da incompletude das redes de infraestrutura urbana.

O que se pode observar é que teve houve um grande avanço em relação ao número de legalização de habitações em área pública na cidade. Segundo Barreto (2011) apud Souza (2007), entre 1980 a 2001 foram deferidos 7.000 Títulos de Posse por meio do Programa Municipal de Legalização Fundiária e segundo a extinta SINDEC (2016), entre 2013 e 2016 foram concedidos 30 mil Títulos de Posse em Salvador. Contudo, o Programa Casa Legal ainda não avançou em relação a contemplar outros usos que não o habitacional e no atendimento à moradias que ultrapassem $250 \mathrm{~m}^{2} \mathrm{em}$ casos do proprietário possuir outro imóvel.

\subsection{MORAR MELHOR}

O programa, lançado em 2015 , tem como objetivo realizar melhorias em residências precárias que, por vezes, não possuem reboco, além de realizar reparos nas condições sanitárias dessas unidades, podendo chegar em até $R \$ 5.000,00$ por 
moradia. Segundo Seinfra (2017, p. 1), os 163 bairros de Salvador selecionados para intervenção foram escolhidos de acordo com alguns critérios:

Os bairros foram selecionados baseados em dados do IBGE de 2010, e utilizado os critérios de predominância de domicílios com alvenaria sem revestimento, pessoas abaixo da linha de pobreza, maior densidade habitacional e maior predominância de mulheres chefe de família.

De acordo com a Prefeitura de Salvador, até maio de 2016 o programa já tinha realizado 4.119 reformas e havia 5.922 intervenções em andamento em 47 bairros da cidade.

\subsection{PROGRAMA MINHA CASA MINHA VIDA}

É um programa do Governo Federal que promove o acesso à moradia a partir da construção de habitações, criado pela Lei n. 11.977 de 7 de julho de 2009, para as famílias de renda até $\mathrm{R} \$ 1.800,00$, Faixa 1 , denominado de interesse social. As operações são feitas com recursos do Fundo de Arrecadamento Residencial - FAR e as outras faixas são atendidas por meio de financiamento da Caixa Econômica Federal. Foram entregues, em Salvador, pelo PMCMV, desde 2010 até 2016, 13.429 unidades habitacionais da Faixa 1 - interesse social, e na Bahia, 175.395 unidades incluindo todas as faixas, segundo a CAIXA (2016). Com o advento da Portaria n.. 168 de abril de 2013, do Ministério das Cidades, pode-se destacar a obrigatoriedade de realizar ligações domiciliares de abastecimento de água e energia elétrica, pavimentação asfáltica definitiva (ruas asfaltadas), iluminação pública, dispor de áreas destinadas a comércio local.

Cabe, ainda, a realização de uma proposta e, consequentemente, de um Instrumento de Compromisso para atendimento da demanda por equipamentos e serviços públicos e urbanos para atender a população do empreendimento e entorno, o que não estava previsto anteriormente. Essa mudança positiva poderá chegar mais perto do objetivo de proporcionar, realmente, uma moradia digna, mudando o cenário atual de construção de habitação sem infraestrutura básica, sem serviços e comércio 
próximos, localizados em locais distantes dos centros e com acessos precários. Para exemplificar essa produção em massa de bairros dormitórios do Programa Minha Casa Minha Vida, cita-se empreendimentos habitacionais implantados na região de Ipitanga que abrange Salvador, Lauro de Freitas e Simões Filho. Segundo Arruda (2015), a região era considerada área rural até 2007 quando o PDDU/2008 a tornou urbana.

Contudo, a região permaneceu sem infraestrutura e sem características urbanas, e, além disso, possui um aterro sanitário que não poderia estar em área urbana, e, também, localiza-se dentro da Área de Proteção Ambiental (APA) Joanes-Ipitanga que é uma área de preservação ambiental dos mananciais dos Rios Joanes e Ipitanga importantes para o abastecimento de água da Região Metropolitana de Salvador. Na região de Ipitanga foram implantados, e alguns ainda não entregues, vinte e três empreendimentos, totalizando 12.306 unidades habitacionais, como mostra a Figura 3 (ARRUDA, 2015). Dentre eles, apenas um empreendimento, o Residencial Coração de Maria, entregará vinte e seis equipamentos de lazer, área institucional, área comercial e serviços básicos (energia elétrica, água e esgotamento sanitário, limpeza urbana, coleta de lixo doméstico e transporte urbano) como mostra a Figura 04. 
Figura 3 - Empreendimentos do programa Minha Casa Minha Vida na Região de Ipitanga e Adjacências (Lauro de Freitas e Simões Filho)

Tabela 03 - Empreendimentos do programa Minha Casa Minha Vida na Região de Ipitanga Adjacências (Lauro de Freitas e Simões Filho)

\begin{tabular}{|c|l|c|}
\hline Município & \multicolumn{1}{|c|}{ Empreendimento } & Unid. Hab. \\
\hline \multirow{5}{*}{ Salvador } & Residencial CEASA I & 499 \\
\cline { 2 - 3 } & Residencial CEASA II & 500 \\
\cline { 2 - 3 } & Residencial CEASA III, IV e V & 888 \\
\cline { 2 - 3 } & Residencial Coração de Maria & 1.800 \\
\cline { 2 - 3 } & Residencial Bosque das Bromélias 1 & 340 \\
\cline { 2 - 3 } & Residencial Bosque das Bromélias 2 & 300 \\
\cline { 2 - 3 } & Residencial Bosque das Bromélias 3 & 380 \\
\cline { 2 - 3 } & Residencial Bosque das Bromélias 4 & 500 \\
\cline { 2 - 3 } & Residencial Bosque das Bromélias 5 & 500 \\
\cline { 2 - 3 } & Residencial Bosque das Bromélias 6 & 380 \\
\cline { 2 - 3 } & Residencial Quinta da Glória Etapa 1 & 500 \\
\cline { 2 - 3 } & Residencial Quinta da Glória Etapa 2 & 440 \\
\cline { 2 - 3 } & Residencial Quinta da Glória Etapa 3 & 380 \\
\hline \multirow{5}{*}{ Lauro de Freitas } & Residencial Lauro de Freitas Setor A & 490 \\
\cline { 2 - 3 } & Residencial Lauro de Freitas Setor B & 503 \\
\cline { 2 - 3 } & Residencial Lauro de Freitas Setor C & 474 \\
\cline { 2 - 3 } & Residencial Lauro de Freitas & 406 \\
\hline & Residencial Ipitanga & 600 \\
\cline { 2 - 3 } & Residencial Parque Universitário I & 500 \\
\cline { 2 - 3 } & Residencial Parque Universitário II & 500 \\
\cline { 2 - 3 } & Residencial Pitanguinha & 486 \\
\cline { 2 - 3 } & Residencial Simões Filho I & 480 \\
\cline { 2 - 3 } & Residencial Simões Filho II & 460 \\
\hline \multirow{5}{*}{ Total } & \\
\hline & & 12.306 \\
\hline \multirow{5}{*}{ Simos Filho } & \\
\hline
\end{tabular}

Fonte: Superintendência de Habitação, SEDUR, 2015.

Fonte: Arruda (2015). 
Figura 4 - Subáreas do Residencial Coração de Maria

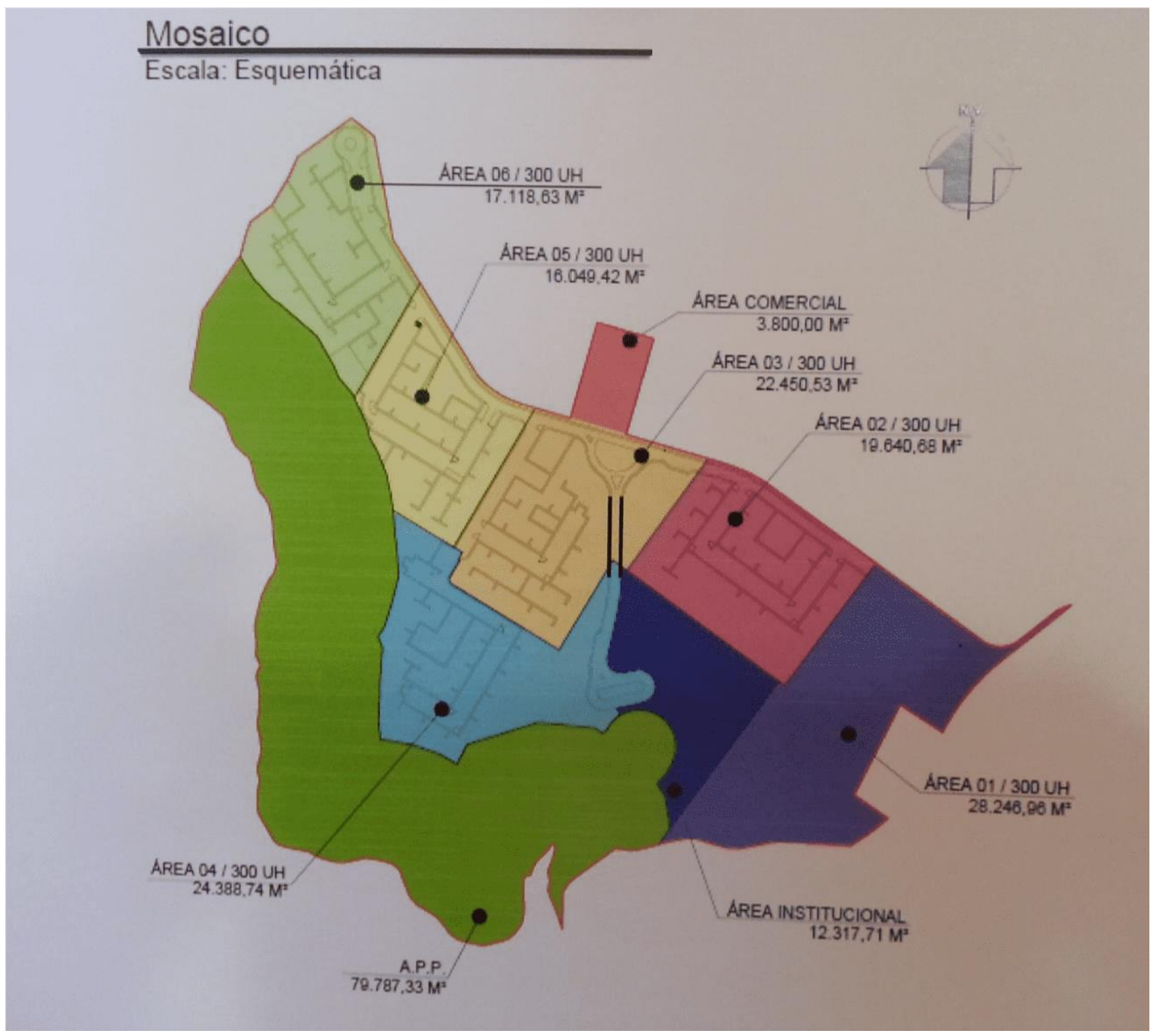

Fonte: Arruda (2015)

Segundo Arruda (2015, p. 28), "os equipamentos mais próximos se localizam em Barro Duro (do outro lado da BA-528), aproximadamente $2,5 \mathrm{~km}$, limite do permitido pela Portaria 168". De acordo com a Portaria n. ${ }^{\circ} 168$ de 12 de abril de 2013 (2013, p.18), "para efeito da apuração da demanda por equipamentos públicos de educação, saúde, lazer e assistência social serão considerados todos os empreendimentos localizados em um raio de dois mil e quinhentos metros". De acordo com Arruda (2015), a Prefeitura Municipal de Salvador, ao elaborar o Diagnóstico por Demanda de Equipamento Públicos, identificou a Creche Geraldo e Helena Belfort para 80 
crianças de 2 a 6 anos, na Estrada da Pedreira; a Escola Juarez Góes com 4 salas na Rua da Pedreira Aratu; a Escola Professor Arx Tourinho com 8 salas na Rua Castro Alves e Nova Esperança e a Creche Amor ao Próximo (Fundação Monte Tabor) na Rua Boa Vista, 12, Nova Esperança.

Ainda segundo Arruda (2015), essas escolas e creches já são deficientes para as comunidades de barro duro e CEPEL e os equipamentos existentes não suprem a necessidade básica das 1.800 famílias do Residencial Coração de Maria, isto sem analisar a situação das famílias dos demais empreendimentos da Região de Ipitanga. Sabe-se que está prevista a construção de uma creche, de uma escola municipal com 15 salas, de uma Unidade de Saúde da Família e de um Centro de Referência de Assistência Social (CRAS). Contudo, segundo Arruda (2015, p. 5):

O Residencial Coração de Maria, em construção, prevê construção de quatro equipamentos públicos os quais não serão suficientes para o novo residencial e para o bairro de Nova Esperança, o qual faz parte. A precariedade em equipamentos públicos e serviços é difundida em toda a região de Ipitanga/Nova Esperança, foco desse estudo, que vive isolada da cidade, no extremo norte em fronteira com os municípios de Lauro de Freitas e Simões Filho.

Os dados relatados anteriormente revelam a situação preocupante da região de Ipitanga. Os equipamentos públicos e as áreas comerciais não são suficientes para suprir a demanda dos vinte e três empreendimentos do programa MCMV do local. A produção de habitação de interesse social em locais longínquos e isolados, carentes de serviços e de equipamentos públicos, não cumpre o objetivo de produzir moradia digna podendo causar uma série de outros problemas sociais para a população instalada em Ipitanga como, por exemplo, exclusão social e espacial, abandono das moradias, obstáculo ao desenvolvimento socioeconômico, usos irregulares dos espaços comuns dos empreendimentos, além de insatisfação em morar em uma habitação incompleta. 


\section{SÍNTESE DOS AVANÇOS ALCANÇADOS PELOS PDDUS EM RELAÇÃO À HABITAÇÃO DE INTERESSE SOCIAL}

O primeiro PDDU de Salvador, Lei Municipal n. $\stackrel{0}{3525 / 1985}$, foi elaborado no final do mandato de Prefeito Manoel Figueiredo, assumindo posteriormente Mário Kertész. Foi um plano importante por criar Áreas de Proteção Sócio Ecológicas que corresponderam, posteriormente, às Zonas Especiais de Interesse Social. Contudo, o PDDU só se consolidou a partir da criação do Estatuto da Cidade, em 2001. O PDDU 2004, Lei n.․ 6.586/2004, na Gestão Municipal do Prefeito Antonio Imbassahy, foi elaborado como revisão do Plano Diretor anterior, tendo como premissa a atualização da base de informações. O Plano não teve participação popular, era extenso e complexo, dificultando a compreensão e leitura, com aprovação fadada à revisão. Segundo Santana e Boaventura (2015):

Tendo em vista o questionamento de diversos aspectos técnicos, entidades populares, por meio do Ministério Público Estadual da Bahia e de sua Promotoria de Justiça, acionaram a Prefeitura de Salvador, requerendo a anulação da proposta do PDDU 2004, designando a UFBA para periciar o Plano e elaborando uma minuta de Termo de Ajustamento e Conduta (TAC). Mas a SEPLAM recusou-se a celebrar o TAC e a Prefeitura enviou o Projeto de Lei para a Câmara Municipal, subjudice. Assim, a Lei Municipal 6.586/04 (PDDU 2004), foi aprovada na Câmara Municipal de Salvador em processo bastante conturbado.

A Lei $n . .97 .400 / 2008$, do PDDU de 2008, foi criada na administração municipal do Prefeito João Henrique. No quesito habitação, segundo a Fundação Instituto de Pesquisas Econômicas (FIPE) (2015), promoveu-se uma ampla revisão dos conceitos, objetivos, procedimentos e instrumentos habilitados, aumentando a capacidade de intervenção; revisão, ampliação e definição de procedimentos das ZEIS como instrumento de Política Urbana. Contudo, segundo Carvalho e CorsoPereira (2013), foi um plano que teve destaque em relação ao mercado imobiliário, referente às definições claras sobre ordenamento territorial (coeficiente de 
aproveitamento) e à fórmula de cálculo do potencial construtivo (negociado pela Transferência do Direito de Construir - TRANSCON), o que permitiu uma verticalização maior na orla da cidade.

Isto resultou, segundo a SINDUSCON (2016), em um aumento de 191\% de empreendimentos em 2008 em relação ao ano anterior. Em 2007 foram 9.068 e em 200817.376 empreendimentos habitacionais. Esses números, infelizmente, não foram em grande parte de habitações de interesse social, mas houve uma redução do déficit habitacional da Região Metropolitana de Salvador. Segundo relatórios da Fundação João Pinheiro, em 2007 havia 141.025 unidades e em 2008 caiu para 116.014. O PDDU atual, Lei n. 9069 de 30 de junho de 2016, recebeu muitas críticas pelos atores técnicos de Salvador pela falta de participação popular verídica, insuficiência de estudos, indefinição de prioridades e metas e ausência de indicação de fonte de recursos. Em relação à habitação, a avaliação técnica feita por Débora Nunes e Ordep Serra (2016), por meio da equipe Participa Salvador, relata que:

No tocante a habitação, a Dra. Ângela Gordilho observou que o PDDU se prende à política de Habitação em vigor, que, no entanto, é "letra morta", pois nada foi executado. Segundo ela, é preciso que se avance no sentido de uma destinação constitucional de recursos para a Habitação, como ocorre no tocante à Saúde e à Educação. Com esse fito, é preciso incluir na Constituição recursos para um Fundo de Habitação, o projeto chamado "PEC da Habitação", impulsionado pelo falecido deputado Zezéu Ribeiro. O trabalho essencial a ser feito em Salvador, e que não está previsto no atual projeto de lei, são as Urbanizações integradas, feitas por bairro, a partir do planejamento efetuado localmente e de forma participativa, permitindo ver o conjunto dos problemas do bairro e operar por prioridades. As áreas que devem ter investimento prioritário devem ser Zeis - Zonas Especiais de Interesse Social, exatamente por serem as áreas mais degradadas da cidade. Destaca-se de positivo no PDDU de Salvador, no tocante à habitação, exatamente o aumento do número de Zeis, para mais de 200. 
Pode-se destacar também a proposta de Cota de Solidariedade, pela qual novos empreendimentos de grande porte, acima de 20 mil metros quadrados construídos, destinam $5 \%$ do valor investido à habitação social.

O PDDU vigente está ainda longe do ideal, com falta de diretrizes claras para aplicação da Política Habitacional de Interesse Social e devido à falta de diretrizes para integração metropolitana a fim de solucionar problemas que fogem dos limites da cidade, como já foi citado neste artigo sobre a região de Ipitanga.

\section{DESAFIOS E PERSPECTIVAS}

A Política Habitacional de Interesse Social em Salvador ainda possui grandes deficiências. A primeira delas, diz respeito à Regularização Fundiária que apesar de ter obtido um grande avanço quanto ao número de titulações entregues, quando comparado ao período de vinte anos, segundo Barreto (2011) apud Souza (2007), entre 1980 a 2001 foram entregues 7.000 Títulos de Posses, e, em três anos, de 2013 a 2016, segundo a extinta SINDEC (2016) foram concedidos 30 mil Títulos de Posse em Salvador, entretanto, ainda não assiste as unidades comerciais e os imóveis implantados em áreas privadas. É necessário medidas jurídicas e administrativas para legalizar esses imóveis, pois é fundamental, para a logística de uma comunidade, ter comércio próximo e possuir o direito de propriedade de um terreno que há muito tempo está sendo usado sua função social.

Sendo assim, este artigo traz como sugestão o aperfeiçoamento do Programa Casa Legal, reiterando a permissão de outros usos que não o de habitação por meio da Autorização de Uso, Permissão de Uso ou Concessão de Direito Real de Uso (CDRU) Onerosa e por meio da criação de um novo instrumento de Política Urbana Municipal que titule os imóveis acima de $250 \mathrm{~m}^{2}$, sob pagamento de taxa mensal proporcional à área excedente. O segundo desafio enfrentado é sobre a ineficiência da política de habitação atuando isoladamente. É importante que sejam feitas intervenções de outras políticas urbanas ao mesmo tempo em que se aplica soluções para o déficit habitacional. O resultado dessa ineficiência é a promoção de moradia inadequada, 
desassistida de infraestrutura urbana e sem serviços básicos (educação, comércio, saúde, transporte e lazer).

Muito além dessa visão urbana existem outros problemas que só fazem aumentar a cada dia e com a falta de moradia digna, educação e saúde adequadas, geram, cada vez mais, violência, violência doméstica, produção de lixo, aumento de índice de natalidade (ausência de planejamento familiar) e diminuição de áreas protegidas. $\mathrm{O}$ terceiro ponto deficiente na habitação soteropolitana é relacionado às medidas preventivas e mitigadoras de novos assentamentos irregulares. É necessário um constante monitoramento do território municipal para a identificação logo no início dessas concentrações informais para poder aplicar as medidas necessárias a cada situação, seja em assistência técnica ou no realojamento das famílias a fim de promover alguma proteção ambiental ou segurança física a essas pessoas em situação de risco.

As soluções habitacionais não precisam se voltar apenas à construção de empreendimentos em locais em que existe a disponibilidade territorial, que, em muitas das vezes, estão distantes dos centros urbanos, mas pode-se utilizar de instrumentos urbanísticos para adensar de forma consciente os locais onde já existe infraestrutura por meio da utilização de imóveis que não estejam cumprindo sua função social, permitindo-se a verticalização de algumas áreas. Para isto, já existem diversos instrumentos que, em geral, não são aplicados em Salvador, como a Cota de Solidariedade (porcentagem destinada à moradia de interesse social e equipamentos públicos); IPTU Progressivo (em imóveis que não cumpram sua função social, podendo ser utilizados para moradia social); Operações Urbanas Consorciadas (com uma porcentagem destinada para moradia social, equipamentos públicos ou infraestrutura que seja necessária); CUEM (Concessão de uso especial para fins de moradia); CDRU; Parcelamento, Edificação ou Utilização Compulsórios e Desapropriação com pagamento mediante títulos da Dívida Pública.

O quarto desafio enfrentado é sobre o Programa Minha Casa Minha Vida, pois ele recebeu diversas críticas sobre a falta de infraestrutura, serviços e localização periférica dos empreendimentos. Primeiramente, a maior parte das cidades brasileiras 
englobam antigas áreas rurais no perímetro urbano para poder utilizá-las para instalar os empreendimentos, devido ao baixo custo de aquisição dos terrenos. Depois, com as novas exigências do Programa para que a Prefeitura entregue um mínimo de equipamentos sociais na vizinhança dos conjuntos habitacionais, essas são áreas que viabilizam financeiramente a execução dessas obras. Esse tipo de implantação gera uma segregação sócio espacial, fazendo com que muitas pessoas não permaneçam nas localidades, tornando o programa ineficiente. Além disso, o objetivo de promover moradia digna está muito longe de ser alcançado, e, assim, deve abranger além da moradia, o abastecimento de serviços urbanos, equipamentos, respeito à cultura local e $o$ acesso aos demais direitos humanos.

\section{CONSIDERAÇÕES FINAIS}

A política habitacional se tornará eficiente somente com a criação de um Plano Integrado com o auxílio de um Sistema Único de Informação que permita planejar, monitorar e fiscalizar com competência. A interação entre os setores de habitação da cidade e interação entre setores diretos e indiretos nas três instâncias (Município, Estado e Federação) permitirá que sejam feitas ações conjuntas das várias políticas urbanas, promovendo, ao mesmo tempo, moradia, serviços urbanos e infraestrutura nas áreas de intervenção, seja na promoção de moradia ou na regularização fundiária. A educação também está presente como um dos pilares do desenvolvimento das comunidades, e, assim, se faz fundamental no âmbito da escolaridade, da intelectualidade e da solidariedade - conceito de uma sociedade mais humana e que ajuda os grupos que se encontram em estado vulnerabilidade.

\section{REFERÊNCIAS}

ARRUDA, C. A. A. Ipitanga, um novo bairro que se forma - Inserção urbana do Programa Minha Casa Minha Vida em Salvador: Implantação do Residencial Coração de Maria. 2015. 61f. Dissertação (Especialização em Assistência Técnica. Habitação e Direito à Cidade) - Universidade Federal da Bahia, Faculdade de Arquitetura e Urbanismo, Salvador, 2015. 
BALTRUSIS, N; MOURAD, L. N. Política habitacional e locação social em Salvador. Caderno CRH, v. 27, n. 71, p. 267-284, 2014.

BARRETO, R. B. F. Pós-regularização fundiária: Transformações no ambiente construído de ocupações informais tituladas, em Salvador - BA (2002-2010). Dissertação (Mestrado) - Universidade Federal da Bahia, Faculdade de Arquitetura e Urbanismo, Salvador, 2011.

BARRETO, R. B. F. Pós-regularização fundiária e Política Municipal de Habitacional. Aula 3: Política Nacional de Habitação. Universidade Salvador, Salvador, 2016.

BARROS, M. Cidades sem Fronteiras. Carlos Leite e Bernardo Chezzi: "Cidades eficientes são as que permitem requalificar as áreas centrais". Revista Veja, São Paulo, 2016. Disponível em: http://veja.abril.com.br/blog/cidades-semfronteiras/urbanismo/carlos-leite-e-bernardo-chezzi-cidades-eficientes-sao-as-quepermitem-requalificar-as-areas-centrais. Acesso em: 18 dez. 2016.

BRASIL. Constituição da República Federativa do Brasil de 1988. Disponível em: http://www.planalto.gov.br/ccivil_03/constituicao/constituicaocompilado.htm. Acesso em: 18 dez. 2016.

BRASIL. Lei no $\mathbf{1 0 . 2 5 7}$ de 10 de julho de 2001. Regulamenta os arts. 182 e 183 da Constituição Federal, estabelece diretrizes gerais da política urbana e dá outras providências. Disponível em: http://www.planalto.gov.br/ccivil_03/leis/LEIS_2001/L10257.htm. Acesso em: 18 dez. 2016.

BRASIL. Ministério das Cidades. Política Nacional de Habitação. 2004. Disponível em:

http://www.seplan.ro.gov.br/Uploads/Arquivos/PDF/Conf.\%20Cidades/ministerio/4Pol \%C3\%ADticaNacionalHabitacao.pdf. Acesso em: 18 dez. 2016. 
BRASIL. Lei no 11.124 de 16 de junho de 2005. Dispõe sobre o Sistema Nacional de Habitação de Interesse Social - SNHIS, cria o Fundo Nacional de Habitação de Interesse Social - FNHIS e institui o Conselho Gestor do FNHIS. Disponível em: http://www.planalto.gov.br/ccivil_03/_ato2004-2006/2005/lei/111124.htm. Acesso em: $18 \mathrm{dez} .2016$.

BRASIL. Lei 11.977 de 7 de julho de 2009. Dispões sobre o Programa Minha Casa Minha Vida - PMCMV. Disponível em: http://www.planalto.gov.br/ccivil_03/_ato20072010/2009/lei//11977.htm. Acesso em: 18 dez. 2016.

BRASIL. Ministério das Cidades. Portaria n.o 168 de 12 de abril de 2013a. Disponível em: https://central3.to.gov.br/arquivo/176707/. Acesso em: 18 dez. 2016.

BRASIL. Secretaria de Direitos Humanos da Presidência da República. Direito à moradia adequada. Brasília: Coordenação Geral de Educação em SDH/PR, Direitos Humanos, Secretaria Nacional de Promoção e Defesa dos Direitos Humanos, 2013b. Disponível em: http://www.sdh.gov.br/assuntos/bibliotecavirtual/promocao-edefesa/publicacoes-2013/pdfs/direito-a-moradia-adequada. Acesso em: 19 dez. 2016.

BRASIL. Lei no 9.069 de 30 de junho de 2016. Dispõe sobre o Plano Diretor de Desenvolvimento Urbano do Município de Salvador - PDDU 2016a e dá outras providências. Disponível em: http://www.sucom.ba.gov.br/wpcontent/uploads/2016/07/LEI-n.-9.069-PDDU-2016.pdf. Acesso em: 18 de dez. 2016.

BRASIL. Programa Minha Casa Minha Vida. Brasil, 2016b. Disponível em: http://www.minhacasaminhavida.gov.br/resultados-do-programa.html. Acesso em: 18 jan. 2017.

CARVALHO, I. de.; CORSO-PEREIRA, G. A cidade como negócio. EURE (Santiago), v. 39, n. 118, p. 5-26, 2013.

CYMBALISTA, R; SANTORO, P. F. Planos Diretores: processos e aprendizados. São Paulo: Instituto Pólis, 2009. Disponível em: http://www.polis.org.br/uploads/1010/1010.pdf. Acesso em: 28 dez. 2016. 
FÔNSECA, A. Bahia é um dos que mais investem em habitação. Tribuna da Bahia, 2016. Disponível em: http://www.tribunadabahia.com.br/2016/12/28/bahia-um-dosque-mais-investem-em-habitacao. Acesso em: 28 dez. 2016.

FREIRE, M. C. Da favela ao bairro: limites visíveis da exclusão na área do Costa Azul - Salvador. 2010. 171f. Dissertação (Mestrado em Planejamento Territorial e Desenvolvimento Social) - Universidade Católica do Salvador, Salvador, 2010.

Fundação Instituto de Pesquisas Econômicas (FIPE). Plano Salvador 500. P4.1 Relatório: Avaliação do Pddu e da Louos em vigor e respectivas justificativas e recomendações para a proposta de revisão destes instrumentos. São Paulo, 2015.

Disponível em:

http://www.cms.ba.gov.br/pddu/Avaliacao\%20do\%20PDDU\%20e\%20LOUOS.pdf. Acesso em: 28 dez. 2016.

Fundação João Pinheiro. Déficit habitacional no Brasil. Belo Horizonte, 2016. Disponível em: http://www.fjp.mg.gov.br/index.php/produtos-e-servicos1/2742-deficithabitacional-no-brasil-3. Acesso em: 28 dez. 2016.

GONÇALVES, F. R. Direitos sociais: direito à moradia. Âmbito Jurídico, Rio Grande, XVI, n. 110, 2013.

JÚNIOR, N. S; UZZO, K. A trajetória da Reforma Urbana no Brasil. 2009. Disponível em: http://base.d-p-h.info/pt/fiches/dph/fiche-dph-8583.html. Acesso em: $14 \mathrm{dez}$. 2016.

MENEZES, E. SEINFRA: Coordenação de Habitação. Resumo sobre o Programa Minha Casa Minha Vida. Salvador, 2016.

NASCIMENTO, B. P. Direito fundamental à moradia digna e adequada como instrumento de redução da vulnerabilidade habitacional e promoção da emancipação social. $2003 . \quad$ Disponível em: http://www.adepes.com.br/Arquivo/Documents/PUB/16_4_2013_Artigo\%20- 
\%20Direito\%20Fundamanetal\%20a\%20Moradia\%20Digna.pdf. Acesso em: 19 dez. 2016.

NASCIMENTO, S. do. Reflexões sobre a intersetorialidade entre as políticas públicas. Serviço Social \& Sociedade, n. 101, p. 95-120, 2010.

NUNES, D; SERRA, O. Participa Salvador. Projeto de Lei do PDDU e Salvador: uma avaliação. $2016 . \quad$ Salvador, Disponível em: http://participasalvador.com.br/2016/02/02/professores-debora-nunes-e-ordep-serraavaliam-projeto-de-lei-do-pddu-de-salvador/. Acesso em: 28 dez. 2016.

PENA, R. F. A. Mundo Educação. Reforma Urbana: a luta pela Reforma Urbana perpassa não somente pela distribuição de moradias, mas pela democratização das condições sociais nos espaços das cidades. 2016. Disponível em: http://mundoeducacao.bol.uol.com.br/geografia/reforma-urbana.htm\#disqus_thread. Acesso em: 18 jan. 2017.

ROLNIK, R. Informe de la Relatora Especial sobre una vivienda adecuada como elemento integrante del derecho a un nivel de vida adecuado y sobre el derecho de no discriminación a este respecto. Brasília, 2013. Disponível em: http://direitoamoradia.org/wp-content/uploads/2013/02/A.HRC_.22.46_sp.pdf. Acesso em: 19 dez. 2016.

ROLNIK, R. Blog da Raquel Rolnik. Conselho de Direitos Humanos adota Resolução sobre moradia. São Paulo, 2014. Disponível em: http://direitoamoradia.org/wp-content/uploads/2013/02/A.HRC_.22.46_sp.pdf. Acesso em: 19 dez. 2016.

SALVADOR. Lei $\mathrm{n}^{\circ} 7.400$ de 20 de fevereiro de 2008. Plano Diretor de Desenvolvimento Urbano de Salvador 2008. Diário Oficial do Município Salvador, Poder Executivo, Salvador, 2008a.

SALVADOR. Secretaria Municipal da Habitação. Plano Municipal de Habitação de Salvador, 2008-2025. Salvador, 2008b. Disponível em: 
https://issuu.com/cidadeaberta/docs/sehab_plano_municipal_de_habitacao_. Acesso em: 22 dez. 2016.

SALVADOR. Secretaria Municipal de Infraestrutura, Habitação e Defesa Civil. Minha Casa Minha Vida. Salvador, 2016a. Disponível em: http://casavida.salvador.ba.gov.br/. Acesso em: 22 dez. 2016.

SALVADOR. Secretaria Municipal de Infraestrutura, Habitação e Defesa Civil. Morar Melhor. Salvador, 2016b. Disponível em: http://sindec.salvador.ba.gov.br/index.php/acoes-programas/morar-melhor. Acesso em: 22 dez. 2016.

SALVADOR. AGECOM. Morar Melhor já beneficia 18 mil famílias em Salvador. Salvador, 2016c. Disponível em: http://www.comunicacao.salvador.ba.gov.br/index.php/todas-as-noticias-4/48122morar-melhor-ja-beneficia-18-mil-familias-em-salvador. Acesso em: 28 dez. 2016.

SALVADOR. Secretaria Municipal de Infraestrutura, Habitação e Defesa Civil. Notícias. Salvador, 2016d. Casa Legal ultrapassa meta da prefeitura com entregas de hoje (17). Disponível em: http://sindec.salvador.ba.gov.br/index.php/acoesprogramas/morar-melhor. Acesso em: 22 dez. 2016.

SALVADOR. Secretaria Municipal de Infraestrutura, Habitação e Defesa Civil. Casa Legal. Salvador, 2016e. Disponível em: http://sindec.salvador.ba.gov.br/index.php/acoes-programas/casa-legal. Acesso em: 22 dez. 2016.

SANTANA, C. R. S; BOAVENTURA, E. M. Aplicação do estatuto da cidade em Salvador: o discurso e a prática. Revista de Direito da Cidade, v. 7, n. 1, p. 41-70, 2015

SERRA, O. Participa Salvador. Os 21 pecados capitais do PDDU de Salvador. Salvador, 2016.

Disponível

em: 
http://participasalvador.com.br/2016/02/02/professores-debora-nunes-e-ordep-serraavaliam-projeto-de-lei-do-pddu-de-salvador/. Acesso em: 28 dez. 2016.

SINDICATO DA INDÚSTRIA DA CONSTRUÇÃO CIVIL DO ESTADO DA BAHIA. Desempenho do mercado imobiliário da Bahia (ADEMI-BA). SINDUSCON, Salvador, 2008. Disponível em: http://www.sindusconba.com.br/conteudo/pub/003/cont/001636/001636.pdf. Acesso em: 28 dez. 2016.

SOUZA, A. G. As cidades na cidade - aventuras do capital e do trabalho na produção do espaço de Salvador. Salvador: Pró-Reitoria de Extensão da UFBA, 2002.

SOUZA, A. G. Intervenções Recentes em Habitação, Salvador-BA. Faculdade de Arquitetura da UFBA, Salvador, 2001. Disponível em: http://www.habitare.org.br/pdf/publicacoes/arquivos/52.pdf. Acesso em: 19 dez. 2016.

SOUZA, A. G. Invasões e Intervenções Públicas: Uma política de Atribuição Espacial em Salvador (1949-1989). 1990. Dissertação (Mestrado em Planejamento Urbano e Regional) - Universidade Federal do Rio de Janeiro, Rio de Janeiro, 1990.

\section{SOUZA, A. G. Regularização Fundiária na Nova Política Municipal de Habitação} de Interesse Social em Salvador. Disponível em: http://www.veracidade.salvador.ba.gov.br/v2/images/veracidade/pdf/Artigo_Regulariz acao_Fundiaria.pdf. Acesso em: 19 dez. 2016.

UNITED NATIONS. Committe on Economical, Social and Cultural Rights. General Comment № 04: The Right To Adequate Housing. Geneva, 2014. Disponível em: http://www.ohchr.org/Documents/Publications/FS21_rev_1_Housing_en.pdf. Acesso em: 19 dez. 2016.

UOL. Pnda 2013: Cai o número de filhos por mulher e sobe o de casais sem filhos no Brasil. UOL Notícias: Ciência e Saúde, São Paulo, 2014. Disponível em: http://noticias.uol.com.br/saude/ultimas-noticias/redacao/2014/12/17/cai-o-numero- 
de-filhos-por-mulher-e-sobe-o-de-casais-sem-filhos-no-brasil.htm. Acesso em: 01 abr. 2016.

VIEIRA, A. L. N. Lex Boletim. O Direito à Cidade e as Zonas Especiais de Interesse Social: um Olhar sobre o Município de Salvador. Salvador, 2008. Disponível em: http://www.lexboletim.com.br/doutrina_24061427_O_DIREITO_A_CIDADE_E_AS_Z ONAS_ESPECIAIS_DE_INTERESSE_SOCIAL_UM_OLHAR_SOBRE_O_MUNICIPI O_DE_SALVADOR.aspx. Acesso em: 28 dez. 2016.

VILLAGRA, R. M. T. A.; OLIVEIRA, A. M. S. Elementos limitantes da oferta de habitação de interesse social na cidade do Salvador, Ba. Sitientibus, n. 35, p. 29-56, 2006.

\section{APÊNDICE - REFERÊNCIAS DE NOTA DE RODAPÉ}

3. A arquiteta e urbanista foi Relatora Especial da ONU durante 2008 a 2014.

4. Relatório do Relator Especial sobre moradia adequada como componente do direito a um padrão adequado de vida e o direito à não-discriminação a este respeito.

Enviado: Novembro, 2018.

Aprovado: Março, 2020. 